\title{
Calculation of Excavation Force for ISRU on Lunar Surface
}

\author{
Xiangwu (David) Zeng ${ }^{*}$ \\ Dept. of Civil Engineering, Case Western Reserve University, 10900 Euclid Avenue, Cleveland, Ohio 44016-7201 \\ Louis Burnoski ${ }^{\dagger}$ \\ Dept. of Civil Engineering, Case Western Reserve University, 10900 Euclid Avenue, Cleveland, Ohio 44016-7201 \\ Juan, H. Agui \\ NASA Glenn Research Center, Microgravity Science Division, 21000 Brookpark Rd., Cleveland, OH 44135 \\ and \\ Allen Wilkinson ${ }^{\S}$ \\ NASA Glenn Research Center, Microgravity Science Division, 21000 Brookpark Rd., Cleveland, OH 44135
}

\begin{abstract}
Accurately predicting the excavation force that will be encountered by digging tools on the lunar surface is a crucial element of in-situ resource utilization (ISRU). Based on principles of soil mechanics, this paper develops an analytical model that is relatively simple to apply and uses soil parameters that can be determined by traditional soil strength tests. The influence of important parameters on the excavation force is investigated. The results are compared with that predicted by other available theories. Results of preliminary soil tests on lunar stimulant are also reported.
\end{abstract}

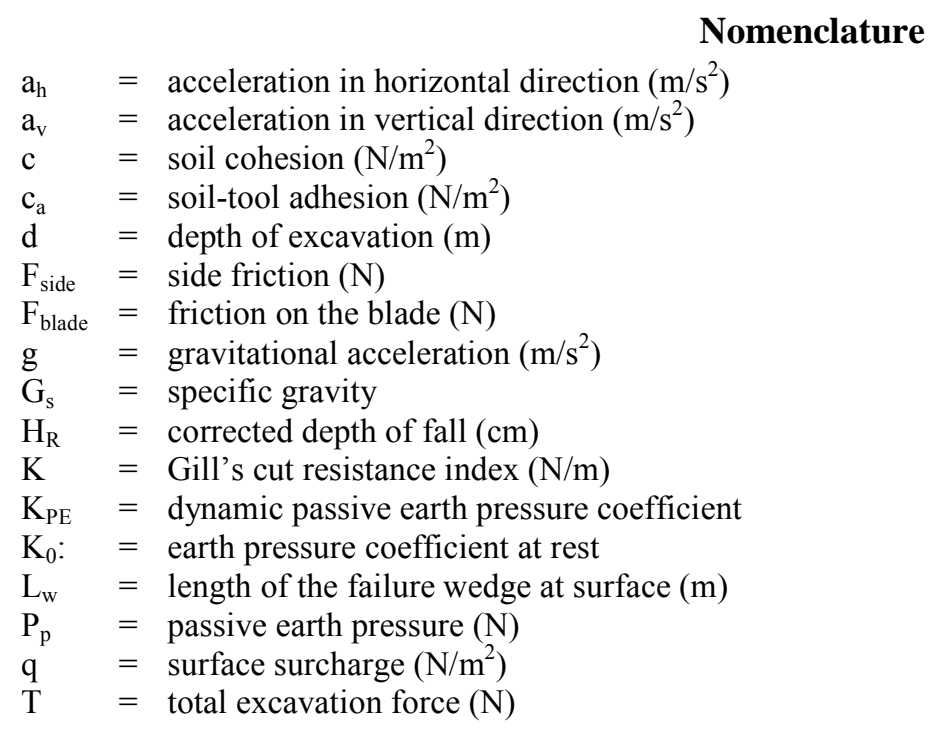

\footnotetext{
* Professor, Dept. of Civil Engineering, Case Western Reserve University, 10900 Euclid Avenue, Cleveland, Ohio 44016-7201.

${ }^{\dagger}$ Graduate Student, Dept. of Civil Engineering, Case Western Reserve University, 10900 Euclid Avenue, Cleveland, Ohio 44016-7201.

$\$$ Research Scientist, NASA Glenn Research Center, Microgravity Science Division, 21000 Brookpark Rd., Cleveland, Ohio 44135, AIAA Member.

$\S$ Research Scientist, NASA Glenn Research Center, Microgravity Science Division, 21000 Brookpark Rd., Cleveland, Ohio 44135, AIAA Member.
} 


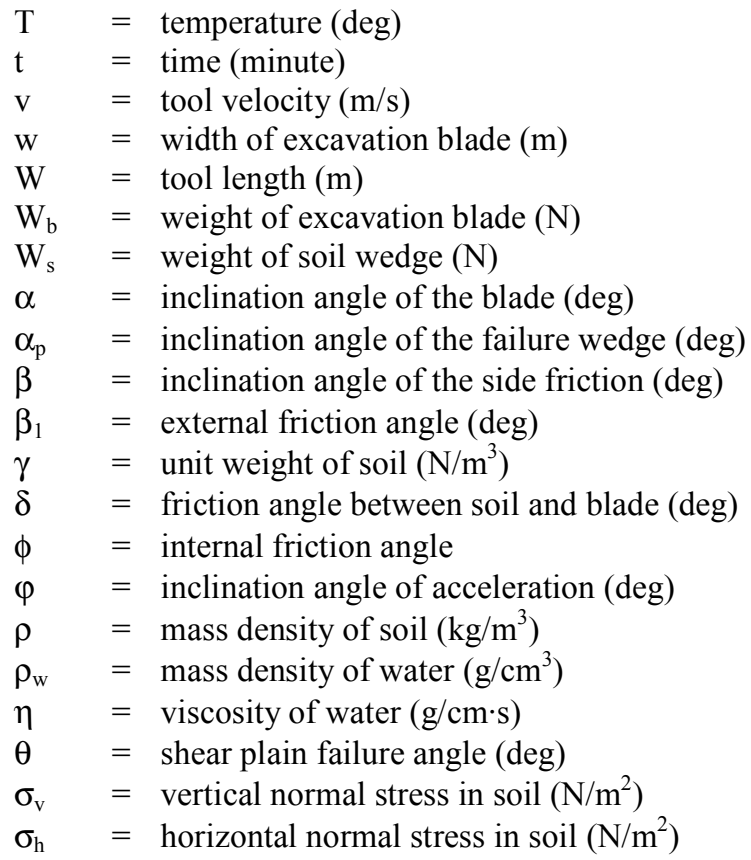

\section{Introduction}

$\mathrm{O}$ ne of the crucial operations for the next manned mission to the moon is the in-situ resource utilization (ISRU), which requires to obtain critical energy sources and life supporting materials such as oxygen and hydrogen from the surface regolith on the moon. In order to design excavation tools for digging and pushing lunar regolith for in-situ resource utilization (ISRU) applications, the excavation force that may encountered by the tools need to be accurately calculated. Over the years, four two-dimensional models have been developed to estimate the excavation force. These are the ones developed by Gill and Vanden Berg ${ }^{1}$, Swick and Perumpral ${ }^{2}$, McKyes and Edwards ${ }^{3}$, and the Martin-Marietta Corporation ${ }^{4}$ in association with the Colorado School of Mines for the design of the Viking Mars exploration probes.

Even though these models have been developed and applied quite frequently, most of them are empirical and use parameters difficulty to determine in laboratory. Therefore, there is the urgent need to develop a model to calculate the excavation force based on principles of soil mechanics, which should be relatively easy to use and parameters be easy to obtain using conventional soil tests. In addition, this model needs to be validated by other commonly used engineering methods such as finite element method and laboratory measurements. In this paper, an analytical model that is relatively simple to apply and uses soil parameters that can be determined by traditional soil strength tests is developed. The influence of important parameters on the excavation force is investigated. The results are compared with that predicted by other four available models.

\section{Results of Preliminary Tests on Simulants}

Since only a few kilograms of lunar soil were brought back from the moon, simulants that have properties similar to that of the lunar regolith need to be created so that engineering tests can be conducted to study the conditions that would be expected on the moon. Currently the most commonly used simulant is the JSC1a, which has three subgroups: JSC1a fines, JSC1a very fines, and JSC1a. Particle size analysis was conducted on the fines in JSC1a fines and very fines at the geotechnical laboratory of Case Western Reserve University. Hydrometer test was used to determine the grain size distribution of fine-grained particles with sizes smaller than $75 \mu \mathrm{m}$ and down to $1 \mu \mathrm{m}$. The principle of hydrometer test is based on Stokes' law, which gives the particle diameter D (mm) as

$$
\mathrm{D}=\sqrt{ }\left\{\left[30 \eta \mathrm{H}_{\mathrm{R}}\right] /\left[981\left(\mathrm{G}_{\mathrm{s}}-1\right) \rho_{\mathrm{w}} \mathrm{t}\right]\right\}
$$

in which $t$ is the time ( $\mathrm{min}$ ) after the beginning of sedimentation, $\mathrm{G}_{\mathrm{s}}$ the specific gravity of the soil particles, $\rho_{\mathrm{w}}$ the unit mass of water $\left(\mathrm{g} / \mathrm{cm}^{3}\right)$ at temperature $\mathrm{T}, \eta$ the viscosity of water $(\mathrm{g} / \mathrm{cm} \cdot \mathrm{s})$ at temperature $\mathrm{T}$, and $\mathrm{H}_{\mathrm{R}}$ the corrected depth of fall $(\mathrm{cm})$. Since most soil particles have irregular shape and EQ.1 was derived for spheres, the particle size 
determined from this method is the equivalent spherical diameter of the particles. The test has been standardized by the American Society for Testing and Materials (ASTM) as ASTM D422. A test takes about 3-5 days to finish. The result on JSCla very fines (VF) is shown in Figure 1.

As shown in the figure, all the fine particles have particle sizes smaller than $25 \mu \mathrm{m}$. There is a wide range of particle size with $\mathrm{D}_{10}=1.2 \mu \mathrm{m}, \mathrm{D}_{30}=3 \mu \mathrm{m}$, and $\mathrm{D}_{60}=6 \mu \mathrm{m}$, where $\mathrm{D}_{10}, \mathrm{D}_{30}$, and $\mathrm{D}_{60}$ means that there are $10 \%, 30 \%$, and $60 \%$ (by weight) of the particles have a size smaller than the number, respectively. The coefficient of uniformity $=D_{60} / D_{10}=5$ and coefficient of curvature $=D_{30}{ }^{2} /\left(D_{10} \cdot D_{60}\right)=1.25$. There are about $6 \%$ of the particles with a size smaller than $1 \mu \mathrm{m}$. Based on particle size analysis, the fines have about $50 \%$ silt and $50 \%$ clay. The soil is classified as a well-graded clay.

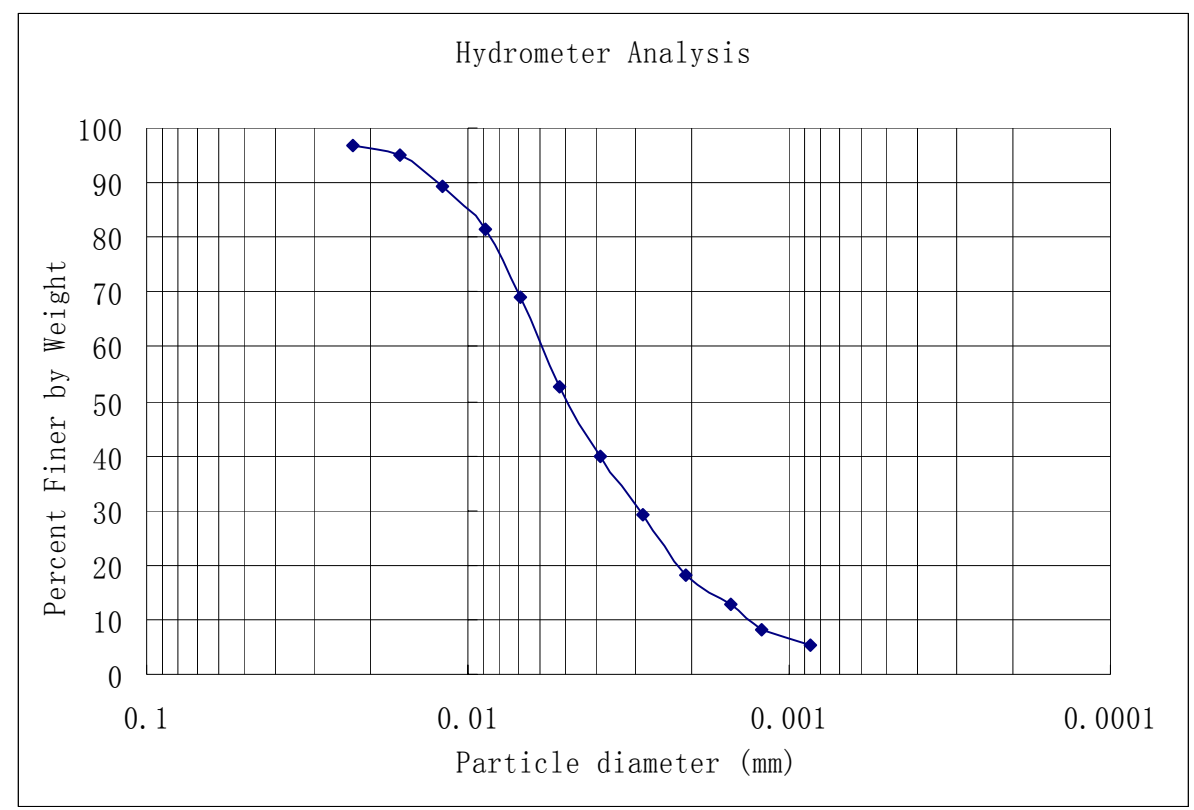

Figure 1. Particle size distribution of JSC1a VF

For the JSC1a fines (F), one sample each was taken at the top and bottom of the storage bucket, respectively. The sample at the top was spooned out the bucket while the sample near the bottom was taken by a mechanical thief. The objective is to see whether there is segregation of particles during the transportation of the fines. The results of the hydrometer tests on JSC1a fines are shown in Figure 2.

As shown in the figure, the particle size distribution of the two samples are almost identical, indicating there is no segregation of particles during the transportation process. There is a wide range of particle size with $\mathrm{D}_{10}=6.2 \mu \mathrm{m}$, $\mathrm{D}_{30}=12 \mu \mathrm{m}$, and $\mathrm{D}_{60}=21 \mu \mathrm{m}$, where $\mathrm{D}_{10}, \mathrm{D}_{30}$, and $\mathrm{D}_{60}$ means that there are $10 \%, 30 \%$, and $60 \%$ (by weight) of the particles have a size smaller than the number, respectively. The coefficient of uniformity $=\mathrm{D}_{60} / \mathrm{D}_{10}=3.4$ and coefficient of curvature $=D_{30}{ }^{2} /\left(D_{10} \cdot D_{60}\right)=1.1$. There are about $2 \%$ of the particles with a size smaller than $1 \mu \mathrm{m}$. Based on particle size analysis, the fines are classified as poorly graded silt.

The specific gravity of the fines is determined using the method described by ASTM D854. It involves the use of Archimedes' principle to determine the volume of irregularly shaped soil particles. The specific gravity is the ratio of mass density of the solid particles divided by the mass density of water at $4^{\circ} \mathrm{C}$. The results of specific gravity test show that the specific gravity of the JSC1a fines is 2.85 . This is typical for silt and clay particles. 


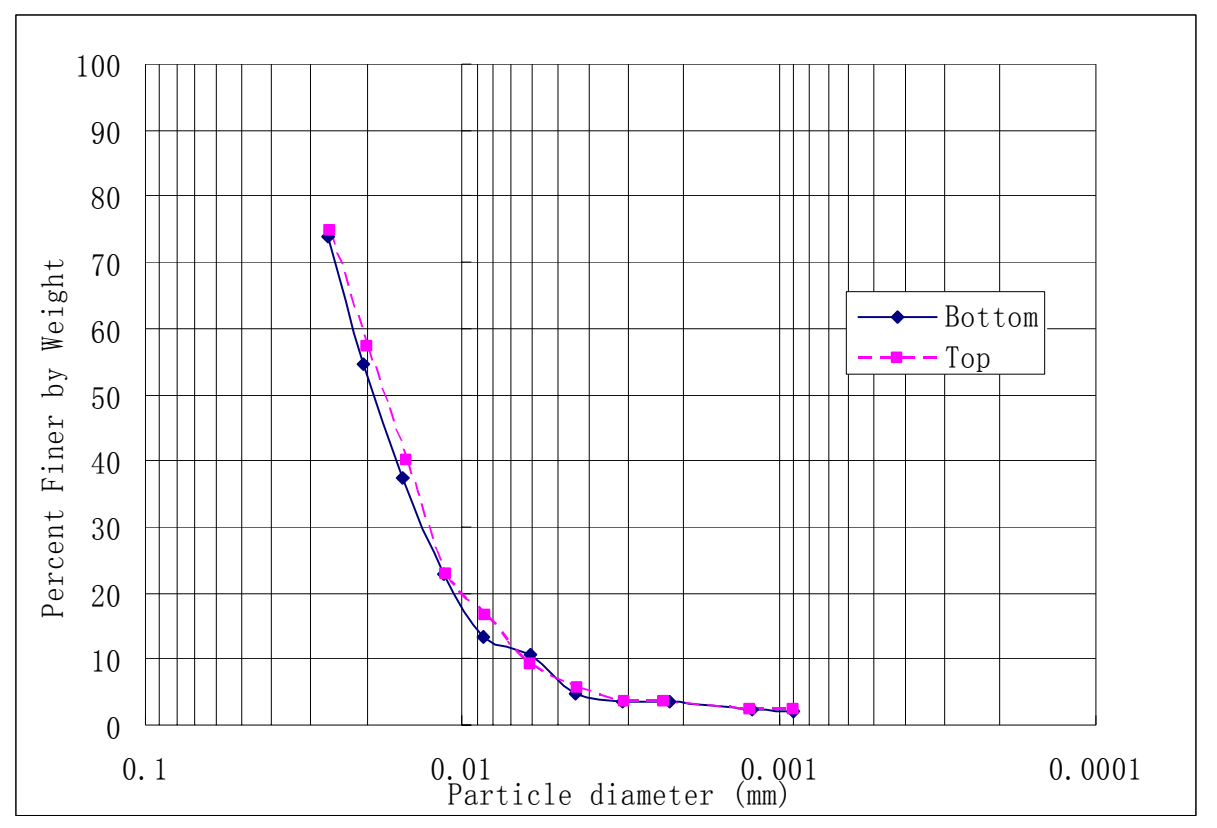

Figure 2. Particle size distribution of JSC1a F

III. A Model to Calculate Excavation Force Based on Principles of Soil Mechanics

This model to calculate excavation force on an excavation blade is based on the principles of soil mechanics. The problem is illustrated in Figure 3.

surcharge $\mathrm{q}$

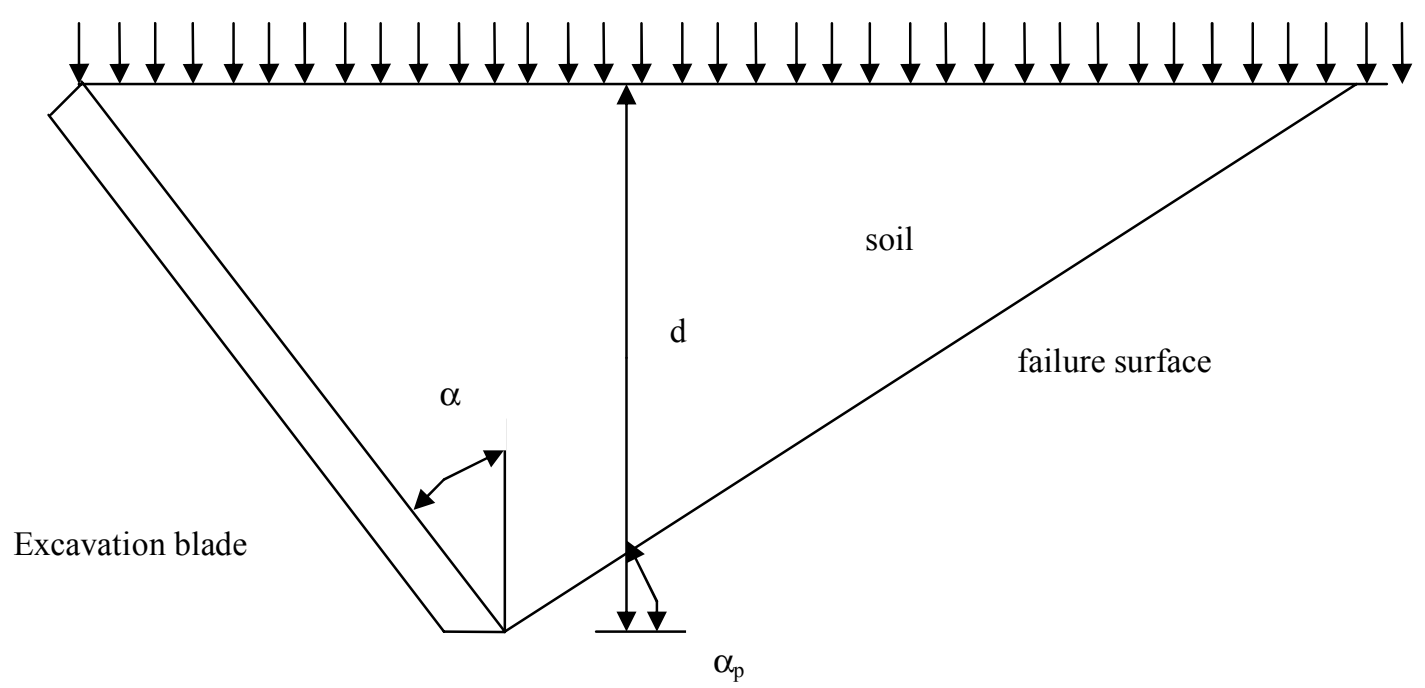

Figure 3. Excavation blade and soil body at failure

The free-body diagram of the blade is shown in Figure 4. 


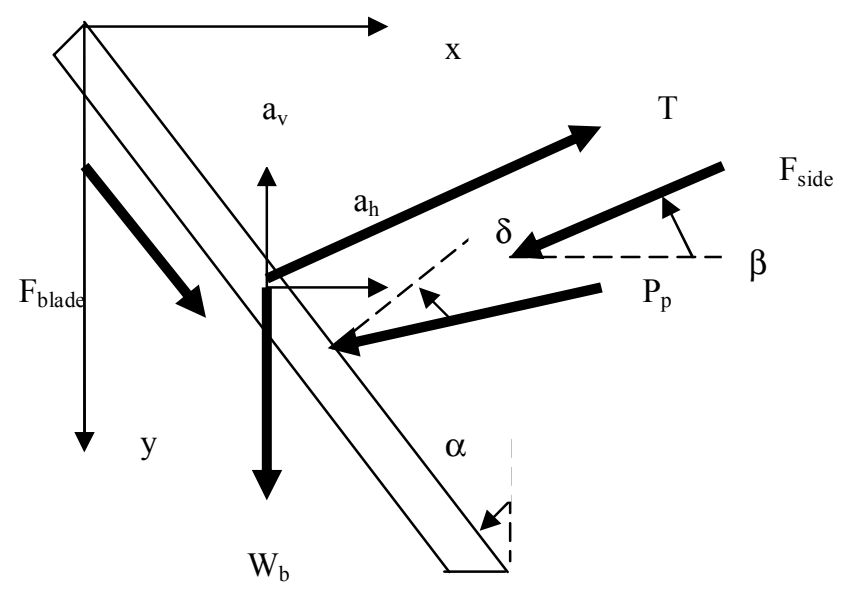

Figure 4. Forces act on the blade

Assuming the blade and the body of soil in failure state have a horizontal acceleration of $a_{h}$ and a vertical acceleration of $a_{v}$, the equations of motion for the blade can be written as:

$$
\begin{aligned}
& \mathrm{T}_{\mathrm{x}}+\mathrm{F}_{\text {blade }} \sin \alpha-\mathrm{P}_{\mathrm{p}} \cos (\alpha-\delta)-\mathrm{F}_{\text {side }} \cos \beta=\left(\mathrm{W}_{\mathrm{b}} / \mathrm{g}\right) \mathrm{a}_{\mathrm{h}} \\
& \mathrm{T}_{\mathrm{y}}-\mathrm{F}_{\text {blade }} \cos \alpha-\mathrm{W}_{\mathrm{b}}-\mathrm{P}_{\mathrm{p}} \sin (\alpha-\delta)-\mathrm{F}_{\text {side }} \sin \beta=\left(\mathrm{W}_{\mathrm{b}} / \mathrm{g}\right) \mathrm{a}_{\mathrm{v}}
\end{aligned}
$$

in which $T_{x}$ and $T_{y}$ are the horizontal and vertical components of $T$, respectively, and $\beta$ is the inclination angle of the side friction force. The equations can be re-written to calculate $\mathrm{T}_{\mathrm{x}}$ and $\mathrm{T}_{\mathrm{y}}$ :

$$
\begin{aligned}
& \mathrm{T}_{\mathrm{x}}=-\mathrm{F}_{\text {blade }} \sin \alpha+\mathrm{P}_{\mathrm{p}} \cos (\alpha-\delta)+\mathrm{F}_{\text {side }} \cos \beta+\left(\mathrm{W}_{\mathrm{b}} / \mathrm{g}\right) \mathrm{a}_{\mathrm{h}} \\
& \mathrm{T}_{\mathrm{y}}=\mathrm{F}_{\text {blade }} \cos \alpha+\mathrm{W}_{\mathrm{b}}+\mathrm{P}_{\mathrm{p}} \sin (\alpha-\delta)+\mathrm{F}_{\text {side }} \sin \beta+\left(\mathrm{W}_{\mathrm{b}} / \mathrm{g}\right) \mathrm{a}_{\mathrm{v}}
\end{aligned}
$$

Then, the total excavation force $\mathrm{T}$ is

$$
\mathrm{T}=\sqrt{ }\left(\mathrm{T}_{\mathrm{x}}^{2}+\mathrm{T}_{\mathrm{y}}^{2}\right)
$$

Three forces need to be calculated in these equations: friction force on the blade $F_{b l a d e}$, passive earth pressure $P_{p}$, and side friction force $\mathrm{F}_{\text {side. }}$ In general, since the blade is moving away from the soil behind the blade, the normal stress on the surface of the blade is expected to be small, resulting in a small frictional resistance. For soil with small cohesion, such as the surface soil expected on the moon, the cohesion component of the friction is also small. Therefore, $\mathrm{F}_{\text {blade }}$ can be ignored without much influence on the calculation.

For calculation of $\mathrm{P}_{\mathrm{p}}$, the widely used Mononobe-Okabe ${ }^{5}$ theory to calculate dynamic earth pressure on a retaining wall during earthquake is modified for this application. It is a pseudo-static type of calculation in which the dynamic effect is taken into account by inertial forces. For the soil wedge in front of the blade shown in Figure 5, assuming a failure state, the passive earth pressure $\mathrm{P}_{\mathrm{p}}$ on the blade is given by

$$
P_{p}=0.5 K_{P E}\left(1+a_{v} / g\right) \gamma d^{2} W+2 c d W \sqrt{ } K_{P E}+K_{P E} q d W
$$

in which $\mathrm{K}_{\mathrm{PE}}$ is the dynamic passive earth pressure coefficient which is given by

$$
\mathrm{K}_{\mathrm{PE}}=\frac{\cos ^{2}(\phi+\alpha+\varphi)}{\cos \varphi \cos ^{2} \alpha \cos (\delta-\alpha-\varphi)\{1-\sqrt{ }[\sin (\delta+\phi) \sin (\phi+\varphi)] /[\cos (\delta-\alpha-\varphi) \cos \alpha]\}^{2}}
$$




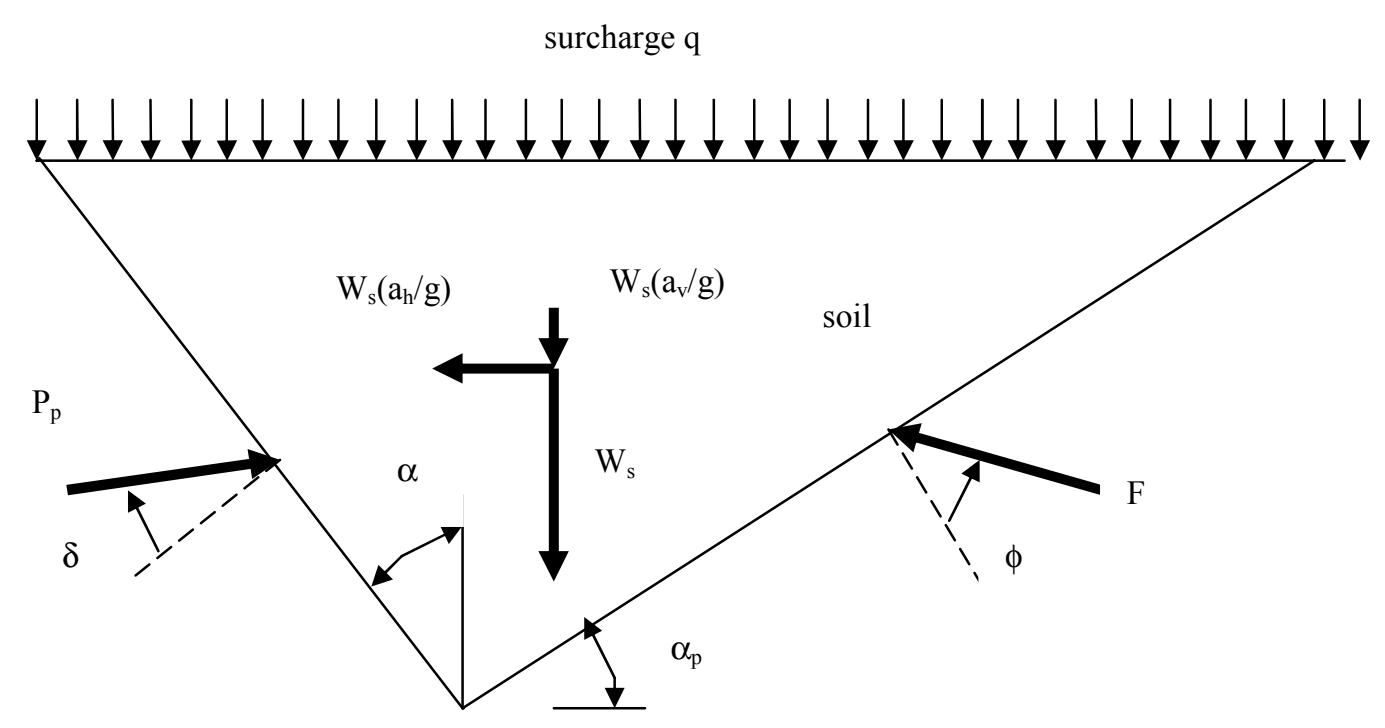

Figure 5. The failure wedge in the soil in front of the blade

where the angle $\varphi$ is the inclination angle of the total acceleration

$$
\varphi=\tan ^{-1}\left[\mathrm{a}_{\mathrm{h}} /\left(\mathrm{g}+\mathrm{a}_{\mathrm{v}}\right)\right]
$$

The critical failure surface is inclined from horizontal by an angle

$$
\alpha_{\mathrm{p}}=-\varphi-\phi+\tan ^{-1}\left\{\left[\tan (\phi-\varphi)+\mathrm{C}_{3 \mathrm{E}}\right] / \mathrm{C}_{4 \mathrm{E}}\right\}
$$

where

$$
\begin{aligned}
& \mathrm{C}_{3 \mathrm{E}}=\sqrt{ }\{\tan (\phi+\varphi)[\tan (\phi+\varphi)+\cot (\phi+\alpha+\varphi)][1+\tan (\delta-\varphi-\alpha) \cot (\phi+\alpha+\varphi)]\} \\
& \mathrm{C}_{4 \mathrm{E}}=1+\{\tan (\delta-\varphi-\alpha)[\tan (\phi+\varphi)+\cot (\phi+\alpha+\varphi)]\}
\end{aligned}
$$

For the side friction calculation, assuming the failure area is the same as the failure wedge in front of the blade and the direction of movement the same as the inclination angle of the wedge or $\beta=\alpha_{p}$, then as shown in Figure 6 , the vertical normal stress at depth $y$ is

$$
\sigma_{\mathrm{v}}=\gamma \mathrm{y}+\mathrm{q}
$$

The horizontal normal stress at the same level is

$$
\sigma_{\mathrm{h}}=\mathrm{K}_{0} \sigma_{\mathrm{v}}=\mathrm{K}_{0}(\gamma \mathrm{y}+\mathrm{q})
$$

The length of the failure wedge at the surface is

$$
\mathrm{L}_{\mathrm{w}}=\mathrm{d}\left(\tan \alpha+\cot \alpha_{\mathrm{p}}\right)
$$

At depth $y$, the length of the failure wedge is

$$
\mathrm{L}(\mathrm{y})=\mathrm{L}_{\mathrm{w}}[(\mathrm{d}-\mathrm{y}) / \mathrm{d}]
$$

6 


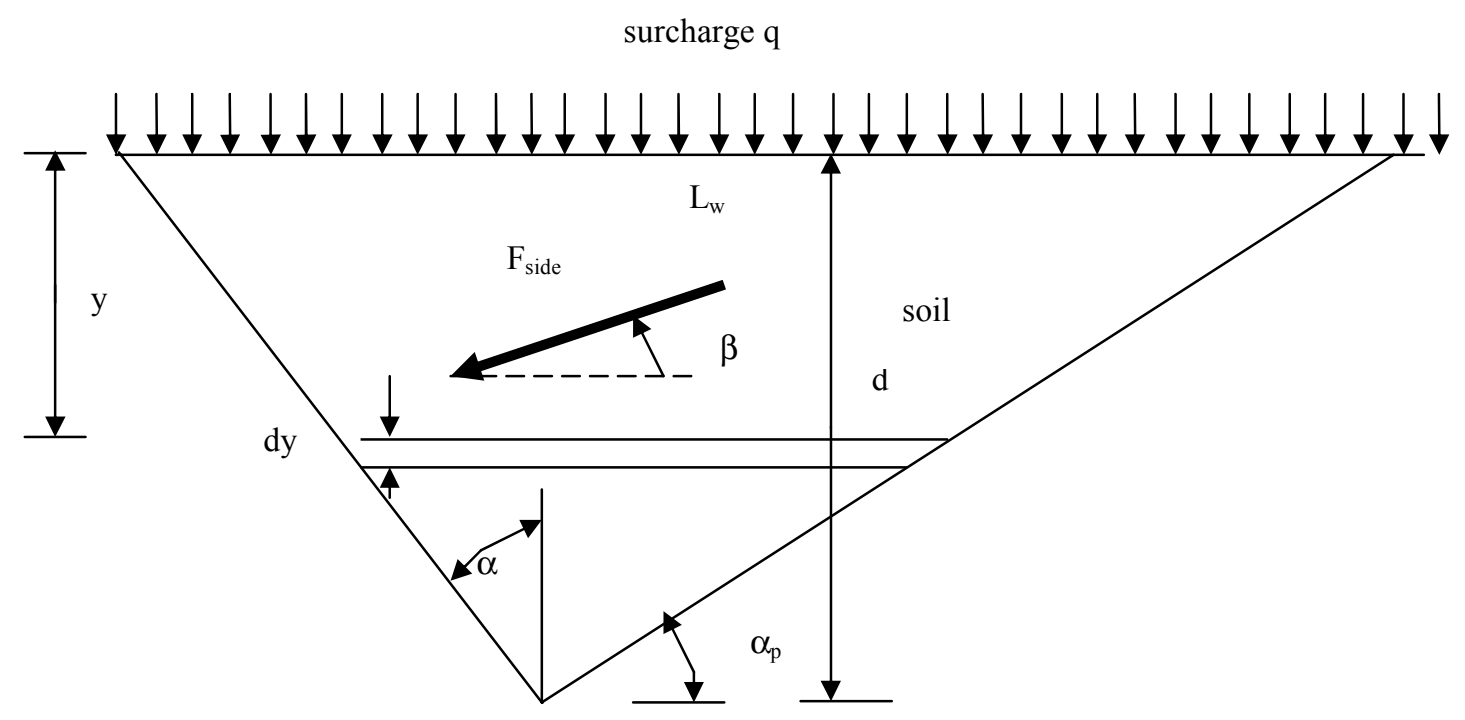

Figure 6. Side frictional force on the soil wedge

For a small slice of the wedge at depth y with a thickness of dy, the side friction force is

$$
\mathrm{dF}_{\text {side }}=2\left(\mathrm{c}+\sigma_{\mathrm{h}} \tan \phi\right) \mathrm{L}(\mathrm{y}) \mathrm{dy}=2\left(\mathrm{c}+\mathrm{K}_{0} \gamma \mathrm{y} \tan \phi+\mathrm{K}_{0} \mathrm{q} \tan \phi\right) \mathrm{L}_{\mathrm{w}}[(\mathrm{d}-\mathrm{y}) / \mathrm{d}] \mathrm{dy}
$$

For the entire side surface

$$
\begin{aligned}
\mathrm{F}_{\text {side }} & =\int_{0}^{\mathrm{d}} 2\left(\mathrm{c}+\mathrm{K}_{0} \gamma \mathrm{y} \tan \phi+\mathrm{K}_{0} \mathrm{q} \tan \phi\right) \mathrm{L}_{\mathrm{w}}[(\mathrm{d}-\mathrm{y}) / \mathrm{d}] \mathrm{dy} \\
& =\mathrm{L}_{\mathrm{w}}\left(\mathrm{cd}+\mathrm{K}_{0} \mathrm{qd} \tan \phi+\mathrm{K}_{0} \gamma \tan \phi \mathrm{d}^{2} / 3\right)
\end{aligned}
$$

Substituting $\mathrm{P}_{\mathrm{p}}$ and $\mathrm{F}_{\text {side }}$ back into equations (4), (5), and (6), the excavation force $\mathrm{T}$ can be determined.

\section{Parametric Study and Interpretation}

The model described above (herein called Zeng model) and the other four existing models can be easily programmed using Excel and the influence of important parameters be studied. Parametric studies were done to demonstrate how these five models respond to variances in their inputs. This gives insight into what are the most important soil parameters for design. The parametric studies hold all inputs constant except for one. The variable input is graphed along the $\mathrm{x}$-axis with the draw bar force along the $\mathrm{y}$-axis. The actual base values for all these inputs are the same as those used in the 2006 Wilkinson-DeGennaro ${ }^{4}$ paper on regolith excavation and traction. Most of these values were taken from the Lunar Sourcebook and represent feasible values for the lunar soil.

$\begin{array}{ll}\text { Tool Width (w): } & 1 \mathrm{~m} \\ \text { Tool Length (W): } & 0.7 \mathrm{~m} \\ \text { Tool Depth }(\mathrm{d}): & 0.5 \mathrm{~m} \\ \text { Tool Velocity }(\mathrm{v}): & 0.1 \mathrm{~m} / \mathrm{s} \\ \text { Moon Gravity }(\mathrm{g}): & 1.63 \mathrm{~m} / \mathrm{s}^{2} \\ \text { Horizontal Acceleration }\left(\mathrm{a}_{\mathrm{h}}\right) & 0 \mathrm{~m} / \mathrm{s}^{2} \\ \text { Vertical Acceleration }\left(\mathrm{a}_{\mathrm{v}}\right): & 0 \mathrm{~m} / \mathrm{s}^{2} \\ \text { Soil Surcharge }(\mathrm{q}): & 1 \mathrm{~kg} / \mathrm{m}^{2}\end{array}$




$\begin{array}{lll}\text { Soil Density }(\rho) \text { : } & 1680 \mathrm{~kg} / \mathrm{m}^{3} \\ \text { Gill's Cut Resistance Index }(\mathrm{K}): 1000 & \mathrm{~N} / \mathrm{m}^{2} \\ \text { Soil Cohesion }(c) \text { : } & 170 \quad \mathrm{~N} / \mathrm{m}^{2} \\ \text { Soil-Tool Adhesion }\left(c_{\mathrm{a}}\right) & 1930 \mathrm{~N} / \mathrm{m}^{2} \\ \text { Rank Angle }(\alpha) & 45 \mathrm{deg} \\ \text { Internal Friction Angle }(\phi) & 35 \mathrm{deg} \\ \text { External Friction Angle }\left(\beta_{1}\right) & 10 \mathrm{deg} \\ \text { Shear Plain Failure Angle }(\theta) & 30 \mathrm{deg} \\ \text { Soil-Blade Friction Angle }(\delta) & 20 \mathrm{deg} \\ \text { At Rest Earth Coefficient }\left(\mathrm{K}_{0}\right) & 0.573\end{array}$

There are several characteristics that are unique to the Zeng model. Most notably is its ability to handle acceleration of the tool blade while the other models assume the soil mass is moving at a constant speed. The Zeng model is also the only model to calculate passive earth pressure. This passive earth pressure must be inclined at a certain angle, which is prescribed. It is often between one half and two-thirds the value of the internal friction angle. The input of this soil-blade friction angle for determining the line of action of passive earth pressure is required. Parametric studies for the Zeng model, broken into its passive pressure and side friction components are shown in Figure 7. It shows how horizontal acceleration, vertical acceleration, the soil-blade friction angle, and external friction angle affects the total excavation force, the passive earth pressure components, and the side friction component, respectively.

Parametric studies of the five soil models are conducted concurrently and the results are shown in Figure 8 . Note that the Swick and Perumpral and McKyes models are quantitatively equal and hence will be represented by the same line throughout this paper. Regarding the graph in the upper left, the Zeng model does not consider the velocity of the toil/soil mass and is thus a horizontal line, while for the other models the value of the draw bar force varies, the way the draw bar force changes is similar. It increases deliberately with increasing velocity, at least on the range shown in the graph. Even at very low speeds, the draw bar force does not differ significantly from its value at moderate speeds. The graph in the upper right, a parametric study of force versus gravity, shows how the models would work under different planetary gravitational fields. Similar to velocity graph, there is a dichotomy of the models, with Zeng and Swick/McKyes models in one group and the Gill and Viking models in another. Another similarity to the velocity; while the models are separated into two sets with similar nominal values, the change in force is a general increase in both cases.

The next two graphs are parametric studies of variance with tool depth and soil density. Both these parameterizations also show the dichotomy between the Zeng/Swick/McKyes models and the Gill/Viking models. Also of note in these two studies, as well as the gravity graph, are the following characteristics. The Zeng model starts out at a lesser value than the Swick/McKyes but increases at a slightly faster rate. Similarly the Viking model starts out at a smaller value than the Gill model but increases moderately quicker. Also, not only do the Gill/Viking models start out at higher nominal values than the Zeng/Swick/McKyes models, but the differences between them increase with the increasing parameter. Variances in soil density and gravity both show linear changes in draw bar force, while variances in soil depth lead to quadratic or quasi-quadratic increases in draw bar force.

The last two charts in Figure 8 show parameterizations of the internal and external friction angles. The Viking model does not consider either friction angle, so it remains a straight line for in both graphs. For changes in both angles, the Gill model gives factor of 2 like differences for the draw bar force as compared to the Swick/McKyes and Zeng models. The Gill model also shows the previously identified pattern of increasing at a greater rate. The Swick/McKyes models behave in a similar fashion to what they did in the previous models but the Zeng model responds differently to angle changes. With changes in internal friction angle the Zeng model starts out at a similar place to the Swick/McKyes models at low friction angles, but increases slower. In the external friction angle parametric study the Zeng model starts out at a similar place and decreases slightly in value as the angle increases.

These last two parametric studies, shown in Figure 9, are the most unique, particularly in the behavior of the Zeng model. The other four models exhibit behavior similar to what we have seen before. The Viking and Gill models give higher values for horizontal force than the Swick/McKyes models. The one notable break from that standard is the linear behavior of the Viking model's variability with rank angle. The Zeng model's dependence on cohesion is much stronger than any of the other models. It shows a rapid increase in the required drawbar force as cohesion increases, having the lowest values for cohesionless soil but the highest values for very cohesive soil. This strong dependence on cohesion shown by the Zeng model might help describe some of the unusual results seen in lunar excavation. Assignment of a value for the apparent lunar cohesion still remains a delicate process. The Zeng model's behavior for rank angle is stranger still, showing a general decrease in force as rank angle increases at small 
angles. As the angle increases, the slope becomes flatter, reaching at minimum at a rank angle of about 57 degrees. Beyond this minimum, horizontal force begins to increase again.
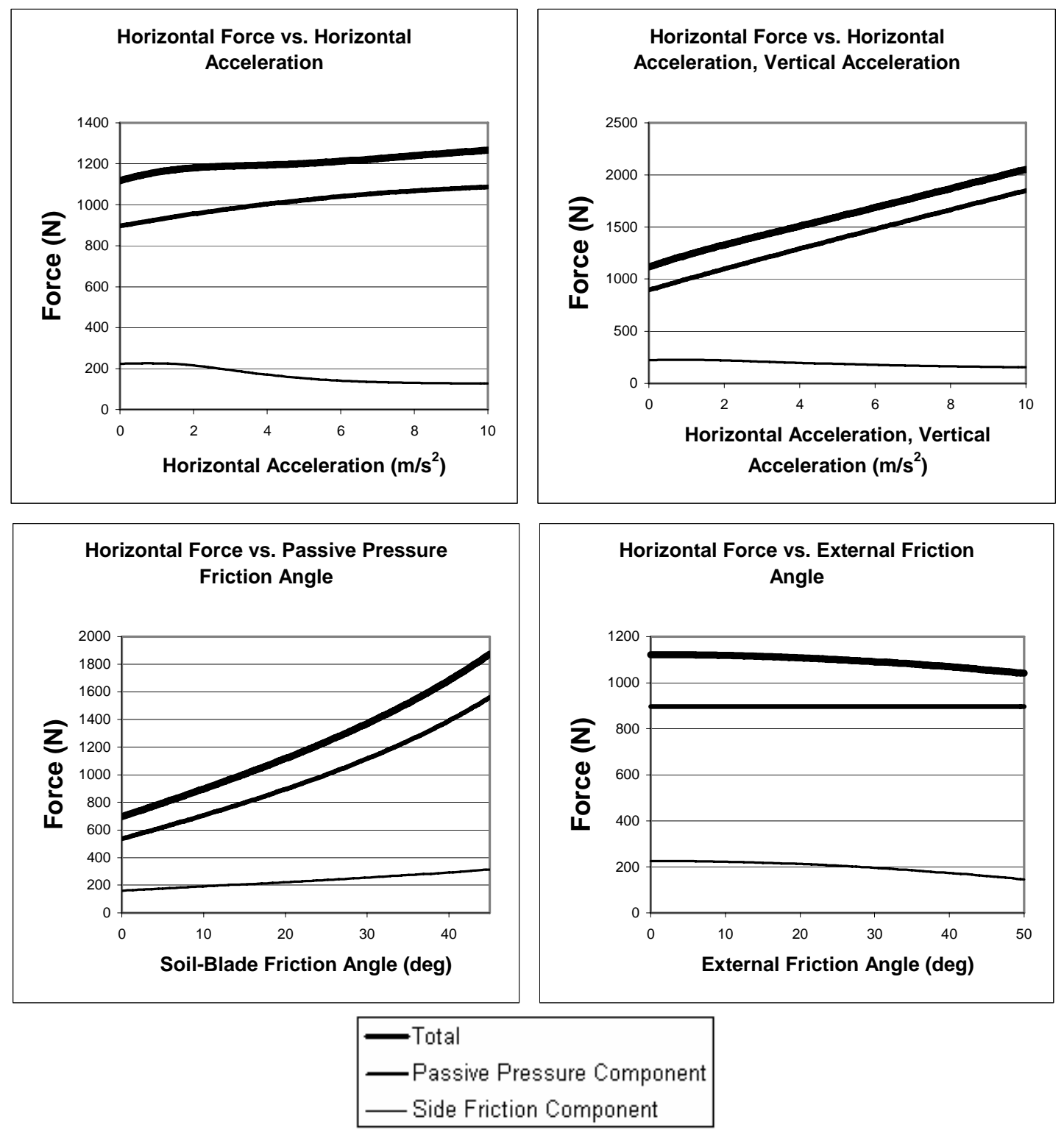

Figure 7. Influence of important parameters on excavation force

9

American Institute of Aeronautics and Astronautics 

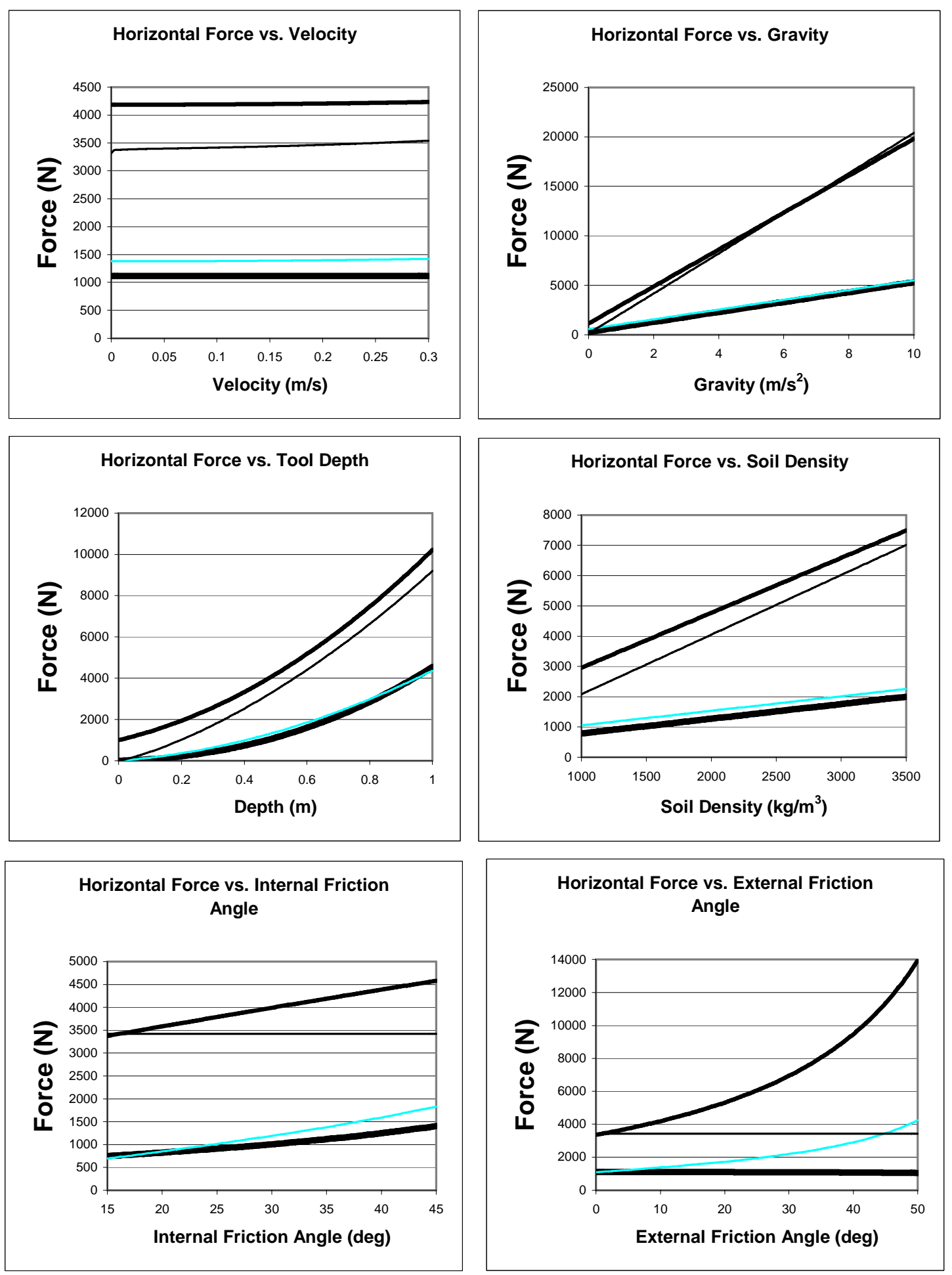

$$
\begin{aligned}
& \text { —Zeng } \\
& \text { — Gill } \\
& \text { Swick/McKyes } \\
& \text { —Viking }
\end{aligned}
$$

Figure 8. Comparison of results of excavation forces by four different models 

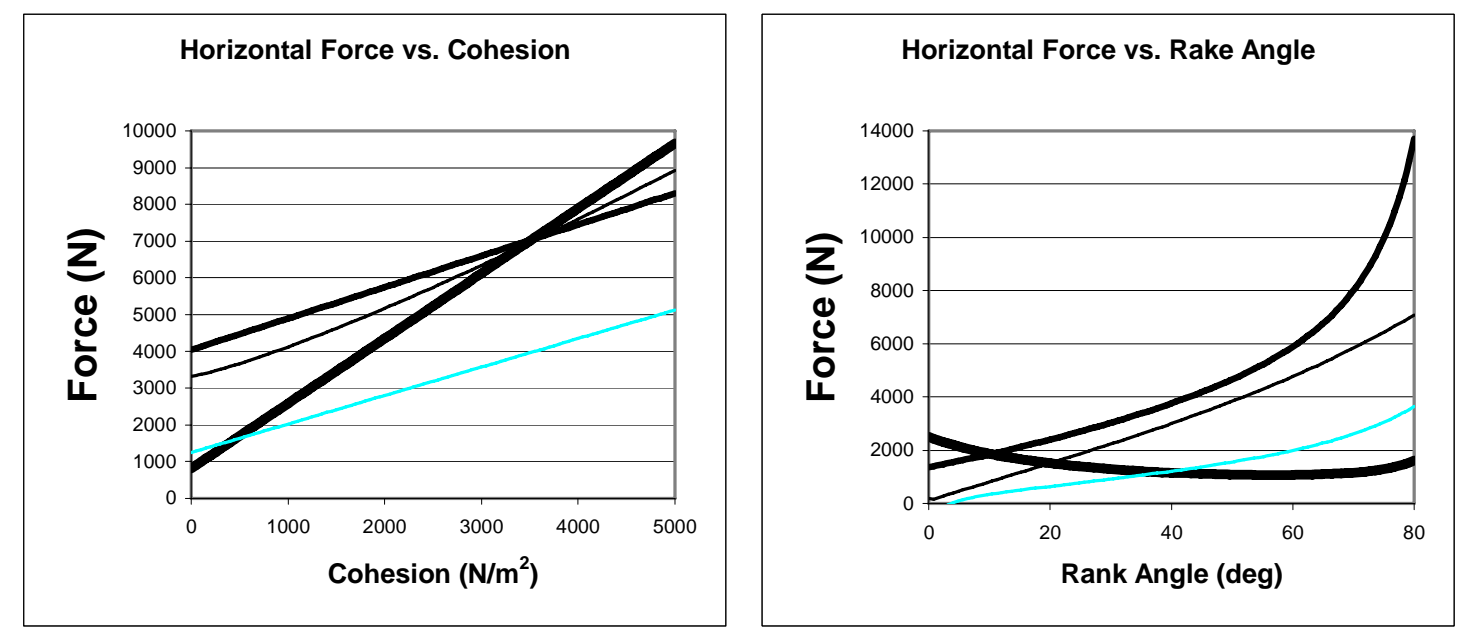

$$
\begin{aligned}
& \text { - Zeng } \\
& \text { - Gill } \\
& \text { Swick/McKyes } \\
& \text { - Viking }
\end{aligned}
$$

Figure 9. Influence of cohesion and rake angle on excavation force

\section{Conclusions}

Based on the results of this study, the following conclusions can be drawn:

1) The particle size analysis has been successfully carried out on JSC1a simulant. The fines and very fines of the simulant has been characterized

2) A new model to calculate the excavation force has been developed. This model is based on the principles of soil mechanics and quite easy to apply. The parameters used in the model can be determined by conventional soil tests. Important parameters that influence the magnitude of the force are identified.

3) Parametric study shows that excavation force calculated by this model is more sensitive to cohesion of the regolith, which may help to explain the high value of excavation forced measured in past mission to the moon.

\section{Acknowledgments}

The first two authors would like to acknowledge the financial support provided by the NASA Glenn Research Center in this research project. All the opinions expressed in the paper are those of the authors and do not represent the official policy of the funding agency.

\section{References}

${ }^{1}$ Gill, W.R. and Vanden Berg, G.E., Agriculture Handbook No. 316, Agricultural Research Service, United States Department of Agriculture, 1968.

${ }^{2}$ Swick, W.C. and Perumpral, J.V., "A model for predicting soil-tool interaction,” Journal of Terramechanics, 25(10:43-56), 1988.

${ }^{3}$ McKyes and Edward, Soil Cutting and Tillage, Developments in Agricultural Engineering 7, Elsevier, Amsterdam, 1985.

${ }^{4}$ Wilkinson, Allen and DeGennaro, Alfred, "Digging and pushing lunar regolith: classical soil mechanics and the forces needed for excavation and traction," NASA Glenn Research Center, Cleveland, OH, 2006.

${ }^{5}$ Kramer, Steven L., Geotechnical Earthquake Engineering, Prentice Hall, Upper Saddle River, New Jersey 07458, 1996. 